\title{
O letramento e o processo de alfabetização nas séries iniciais do ensino fundamental
}

A educação escolar exige redimensionamentos, mudanças efetivas, para que a formação do ser humano seja mais completa, mais coerente, com as exigências sociais e humanas. Pensar no processo de inserção do ser humano na cultura escrita é, sem dúvida, falar de inclusão, de participação social, de cidadania plena. Dessa forma, apresentam-se algumas concepções e práticas pedagógicas recorrentes na área Letramento e Oralidade. Verificar-se-á a relevância das marcas da oralidade, ocasionadas pelos os aspectos fonológicos (a sonoridade do fonema), para a produção escrita, sendo o nosso propósito abrir uma reflexão à prática pedagógica e ensino da Língua Portuguesa nas escolas de ensino fundamental, principalmente nas aulas de produção textual. Nesse sentido, tomaremos por base as bases filosóficas das Escolas de Ensino Fundamental de Santa Catarina, de base Sociointeracionista.

Palavras-chave: Educação; Cultura Escrita; Letramento; Oralidade.

\section{Literacy and the literacy process in the early grades of elementary school}

\begin{abstract}
School education requires resizing, effective change, so that the formation of the human being is more complete, more coherent with social and human demands. To think about the process of insertion of the human being in written culture is undoubtedly to speak of inclusion, social participation, full citizenship. Thus, some recurring pedagogical conceptions and practices are presented in the Literacy and Orality area. It will be verified the relevance of the orality marks, caused by the phonological aspects (the sound of the phoneme), for the written production, being our purpose to open a reflection to the pedagogical practice and the teaching of the Portuguese Language in the elementary schools, mainly in textual production classes. In this sense, we will take as base the philosophical bases of the Elementary Schools of Santa Catarina, of Sociointeracionista base.
\end{abstract}

Keywords: Education; Written culture; Literacy; Orality.

Topic: Práticas, Didática e Metodologias do Ensino

Reviewed anonymously in the process of blind peer.
Received: 09/01/2019

Approved: 08/02/2019
Nicelene Maria Soares

UniGrendal University, Brasil

http://orcid.org/0000-0003-4874-8790

niceleneph@gmail.com

\section{Referencing this:}

SOARES, N. M.. O letramento e o processo de alfabetização nas séries iniciais do ensino fundamental. Educationis, v.7, n.1, p.21-31, 2019 DOI: http://doi.org/10.6008/CBPC2318-3047.2019.001.0003 


\section{INTRODUÇÃO}

Alfabetização e letramento são temas amplamente analisados e discutidos nos meios acadêmicos e profissionais. Mas, embora isso aconteça, o que os censos mostram é que o Brasil precisa avançar consideravelmente nesses aspectos. Para a Sociolinguística, existem inúmeros fatores justificáveis que ocasionam essas marcas da oralidade no momento da produção escrita dos alunos. Assunto esse que causa controvérsia e controvérsias no meio acadêmico e social, entre os Linguistas e Gramáticos ultrapassando as barreiras escolares.

Assim sendo, dispõe-se a pensar a língua no seu meio social e não como um sistema de ordem fechada, que guia o aluno a um Sistema rígido e imutável, mostrando que existem diferentes formas linguísticas de uso da língua e que não se pode entendê-la como dicotômica no continuum 'fala' e 'escrita'. Saber diferenciar a norma culta da norma popular e adequar o seu uso em diferentes situações de produção discursivas é considerado por alguns estudiosos como o empecilho para o avanço educacional do aluno e que o pertencimento ao grupo social de maior prestígio diz respeito ao uso da língua empregada, o mais próximo, da forma contida na gramática.

A criação do SAEB - Sistema Nacional de Avaliação da Educação Básica - pelo Ministério da Educação, nos anos 90, permite obter dados referentes ao desenvolvimento da leitura e da escrita nesse nível de escolaridade e conhecer quais são os principais pressupostos defendidos por esse órgão, quando ele se refere às matrizes de referência da Língua Portuguesa, aplicando-se ao Ensino Fundamental I, ou seja, do 10 ao 5o ano.

Diante disso, o que se pode perceber é que, embora haja muitas iniciativas em prol de um processo de alfabetização e letramento que possibilitem a verdadeira inserção do indivíduo na sociedade, seja nas séries iniciais ou em todo o desenvolvimento escolar, tendo desenvolvido competências linguísticas indispensáveis ao pleno convívio social, o Brasil apresenta ainda altos índices de analfabetos funcionais; ou seja, indivíduos que sabem ler e escrever, mas que não desenvolveram a habilidade de interpretar e usar a língua - leitura e escrita - de maneira sistemática e consciente em seu cotidiano.

Partindo dessa constatação, é de extrema importância, dentre outros aspectos, o investimento na formação dos professores alfabetizadores. O presente texto apresentará elementos de reflexão para os professores e todos os que se interessam pelo assunto, buscando contribuir para uma prática pedagógica inovadora, baseada na reflexão, na criticidade, na ação renovada destinada ao Ensino Fundamental I.

Para tanto, serão analisadas as linhas filosóficas que regem as Escolas de Ensino Fundamental Catarinenses, que atendem educandos do 1음 ao 5o ano dos anos iniciais do Ensino Fundamental e adotam os ideais do sociointeracionismo para as práticas de ensino-aprendizagem das Unidades Escolares. Nesse sentido, abordar-se-ão os conceitos de alfabetização e letramento nas Séries Iniciais, procurando apresentar as visões e controvérsias acerca dessas duas palavras tão usadas ultimamente na área educacional.

Em seguida, será tecida uma breve explanação dos métodos de alfabetização no Brasil a partir da proclamação da República e apresentaremos uma teoria que questiona os métodos considerados 
'tradicionais': a Psicogênese da Língua Escrita, formulada por Emília Ferreiro e Ana Teberosky. Para encerrar o texto, será de grande utilidade uma abordagem sobre Prática em Alfabetização e Letramento nas Séries Iniciais e discutiremos sobre a importância da formação do professor.

\section{METODOLOGIA}

A metodologia do trabalho científico qualitativa está pautada na melhor condução da produção científica e acadêmica, proporcionando ao pesquisador uma padronização na forma como os dados serão coletados e interpretados e, ainda, de que forma os objetivos da pesquisa serão atingidos (PRODANOV et al., 2013). Nesta perspectiva, a definição da metodologia é ímpar para o efetivo descobrimento e desenvolvimento do estudo ora proposto, já que é ela quem dá a diretriz de como os trabalhos serão conduzidos e mensurados.

Para Andrade (1999), o método é uma ordem que deve se impor aos processos necessários para atingir seu objetivo ou o resultado desejado. Com essas citações, podemos ver a importância de termo um método para realizar a pesquisa, para que tenhamos procedimentos a serem adotados para alcançar o objetivo, o que se dá por entender qual o caminho utilizado para responder e resolver à pergunta proposta utilizando as informações levantadas pelo estudo. Portanto, a metodologia é o conjunto do processo pelos quais se torna possível entender uma determinada realidade, produzir determinado objeto ou desenvolver processos e procedimentos para identificação da solução e alcance dos objetivos preestabelecidos pela pesquisa.

Diante da premissa da conceituação da metodologia aplicada à pesquisa científica, em consonância com o que apregoa Gil (2013), quanto à sua natureza este estudo é aplicado, uma vez que os conhecimentos gerados a partir dos achados foram dirigidos à solução de um problema específico em relação à temática estudada. Ou seja, procurou produzir conhecimentos para aplicação prática da legislação trabalhista aplicada à prevenção de acidentes de trabalho.

Concorrendo à execução aplicada do método de pesquisa, o método científico a ser utilizado para elucidação lógica dos materiais pesquisados foi o dedutivo, sugerindo uma análise de problemas que partem do geral para o particular, através de uma cadeia de raciocínio decrescente. Este método, de acordo com Marconi et al. (2017), visa partir de uma premissa geral para um particular, utilizando-se de uma cadeia de raciocínio ilógica estruturada.

Contudo, o estudo também teve emprego do método dialético, já que a dialética fornece as bases para uma interpretação dinâmica e totalizante da realidade da legislação trabalhista, estabelecendo que os fatos do direito não podem ser entendidos quando considerados isoladamente, abstraídos de suas influências políticas, econômicas, culturais etc. O método dialético proporciona uma interpretação sistematizada e ágil das informações colhidas pelo pesquisador, já que considera os fatores sempre inseridos em um contexto global.

Quanto aos seus objetivos, a pesquisa possuiu cunho exploratório e descritivo. Ou seja, é exploratório porque há construção de hipóteses a partir dos problemas propostos, (MARCONI et al., 2017) e é descritivo 
ao passo que expõe as características da legislação trabalhista e as aplica demandando técnicas padronizadas de coleta de dados.

\section{DISCUSSÃO TEÓRICA}

\section{Alfabetização e Letramento nas séries iniciais: reflexões sobre esses conceitos}

A fala e a escrita são duas modalidades distintas, mas que não podemos ignorar as suas semelhanças em aspectos relevantes de uso da língua como afirma Marcuschi (1995),descrevendo que "as diferenças entre fala e escrita se dão dentro do continuum tipológico das práticas sociais e não na relação dicotômica de dois polos opostos" (KOCH et al., 2009).

Ao longo das últimas décadas, a alfabetização tem se tornado um tema de constantes pesquisas, debates e confronto de ideias que exige dos professores certo ecletismo para acompanhar tudo que é divulgado sobre o assunto na mídia, confrontando com a prática existente e incorporando nessa quando necessário. Cabe dizer que tal processo se inicia no 10 ano do E.F., e pode se estender por todo Ensino Fundamental I e II, Ensino Médio e, inclusive no Ensino Superior.

Ler e escrever, segundo Goodmann (1967), são atividades comunicativas que exigem conhecimentos da língua por se tratar de uma estrutura integrada, na qual os aspectos sintáticos, semânticos e fonológicos interagem para atribuir significado ao que está graficamente representado no texto escrito, não estando restritas somente aos primeiros anos das Séries Iniciais, mas sim em toda sua sequência escolar.

Na década de 80, o debate se limitava à qualidade dos métodos sintéticos e analíticos. A partir daí, iniciou-se um novo foco de debate: o construtivismo. Esse método defendia uma aprendizagem centrada no exercício operacional e evolutivo da inteligência: “(...) o ensino deve priorizar o desenvolvimento da capacidade de operar, de estabelecer relações. Os fatos ou as informações só têm sentido na medida em que são compreendidos e, ao sê-lo, aprimoram a capacidade de compreensão do sujeito" (FRANCO et al., 1997). Soares (2007) afirma que a alfabetização ainda está à espera de uma compreensão plena de seu processo, visto que ela precisa de método e teoria. Método porque ninguém aprende a ler e a escrever sem uma orientação segura do processo de aprendizagem, e teorias porque fundamentam o processo.

Soares (2007) também defende que a alfabetização é um processo de representação de fonemas em grafemas e vice-versa, mas é também um processo de compreensão/expressão de significados por meio do código escrito, já que a língua escrita não é uma transcrição da fala, há também uma especificidade morfológica, sintática e semântica da língua escrita: não se fala como se escreve, mesmo quando se escreve em contextos informais (SOARES, 2007). Por isso, a alfabetização exige a aquisição de um conjunto de habilidades que contemplem as diferentes facetas da língua.

Entende-se que as possibilidades a serem trabalhadas com o aluno nos critérios de produção textual escrita e oral devem ser intercaladas pelo professor, para que o aluno possa dominar as duas modalidades discursivas, tanto as de prestígio social quanto as estigmatizadas socialmente, tendo o domínio do conhecimento formal ou informal. 
Nesse viés, o educando poderá saber se nas circunstâncias de uso linguístico, preparando-se para lidar com essas situações, não excluindo como 'errado' o aluno que carrega para o texto escrito a marca da oralidade, uma vez que seu texto significa dentro da condição de produção do aluno. Assim, ao professor cabe orientar, educando com subsídio teórico metodológico, para que tal texto contemple o gênero textual desejado (FERREIRO et al.,1999). Dentro do tratamento dado à linguagem durante o Ensino Fundamental, há que se ressaltar os quesitos pertinentes às orientações didáticas específicas para alguns conteúdos em relação à variação linguística, destacando a inovadora visão a respeito das variantes linguísticas.

Frente aos fenômenos da variação, não basta somente uma mudança de atitudes; a escola precisa cuidar para que não se reproduza em seu espaço a discriminação linguística. Desse modo, não pode tratar as variedades linguísticas que mais se afastam dos padrões estabelecidos pela gramática tradicional e das formas diferentes daquelas que se fixaram na escrita como se fossem desvios ou incorreções. E não apenas por uma questão metodológica: é enorme a gama de variação e, em função dos usos e das mesclas constantes, não é tarefa simples dizer qual é a forma padrão (efetivamente, os padrões também são variados e dependem das situações de uso). Além disso, os padrões próprios da tradição escrita não são os mesmos que os padrões de uso oral, ainda que haja situações de fala orientadas pela escrita.

Na BNCC, bem como ocorria nos Parâmetros Curriculares Nacionais, o texto perfaz o ponto fulcral para demarcação dos eixos dos conteúdos, habilidades e objetivos, considerando-se, a unidade textual desde seu pertencimento a um gênero discursivo que circula em diversas esferas sociais de atividade, de comunicação e de uso da linguagem (BRASIL, 2017).

Pensar que o processo educacional se molda de acordo com o tempo histórico que se situa, e que se deve aceitar que as mudanças já existem e fazem parte de estudos teóricos, sendo efetivadas em novos modelos educativos, regidos por leis, normativas, parâmetros, diretrizes, entre outras ferramentas que garantem o direito do aluno ao ensino de boa qualidade e dentro da sua realidade social. Nessa escala de pensamentos, Kamii (1990) ressalta os dizeres de Piaget ao declarar que "a finalidade dos letramentos linguísticos e matemáticos deve ser a de desenvolver a autonomia da criança, que é indissociavelmente social, moral e intelectual".

\section{Leitura e Escrita: habilidades necessárias}

Para aprender a ler e a escrever, é preciso aprender a observar e a fazer levantamento e análise de hipóteses com o objetivo de buscar solucionar os conflitos cognitivos e efetivar a aprendizagem. Outro problema presente na alfabetização é em relação às letras, pois essas, para quem ainda não sabe escrever, são apenas representações. $O$ aprendiz precisa entender e saber que cada uma dessas representações, de acordo com as características, vale como símbolo de um som da fala para, a partir disso, conseguir discriminar as formas das letras e distingui-las, já que elas são muito semelhantes ( $p / b, b / d$, etc.) e necessárias à aprendizagem da leitura.

A alfabetização ainda requer a conscientização da percepção auditiva, uma vez que "as letras simbolizam sons de fala e, devido a isso, é necessário saber ouvir as diferenças linguisticamente relevantes entre esses sons, de modo que se possa escolher a letra certa para simbolizar cada som" (LEMLE, 1999). A 
diferença sonora entre as palavras 'pala' e 'fala', por exemplo, ocorre por meio do emprego das consoantes iniciais de cada palavra e das características dessas. Assim, adquirirá a capacidade de escrever quem for capaz de perceber as unidades sucessivas de sons da fala empregadas para emitir as palavras e para distingui-las conscientemente umas das outras. É importante, também, no processo da alfabetização, saber captar o conceito de palavra, pois "ela é o cerne da relação simbólica essencial contida numa mensagem linguística: a relação entre conceitos e sequências de sons da fala" (LEMLE, 1999).

Isso possibilitará aquisição da capacidade de focalizar a palavra enquanto sequência de sons, de estabelecer relação entre significante e significado, construindo, dessa forma, o sistema de representação da leitura e da escrita e de acrescentar palavras à sua escrita, elaborando sentenças e reconhecendo-as a partir das leituras iniciais (FERREIRO et al., 1999).

Tais situações mostram que o processo de alfabetização inclui muitos fatores e exige do alfabetizador a ciência de como ocorre a aquisição do conhecimento, da natureza da realidade linguística envolvida no momento em que acontece a alfabetização e de como ele terá de coordenar o processo de aprendizagem, uma vez que a alfabetização requer a aprendizagem de uma peculiar e muitas vezes "idiossincrática relação fonemas-grafemas, de outro código que tem, em relação ao código oral, especificidade morfológica e sintática, autonomia de recursos de articulação do texto e estratégias próprias de expressão/compreensão" (SOARES, 2007).

Cabe ressaltar, porém, conforme Bagno (2007), que existem duas línguas no Brasil, o português e o vernáculo brasileiro. Sendo o português a representação da língua escrita que segue uma estrutura gramatical normativa estabelecida como acordo ortográfico assinado entre Brasil, Portugal e alguns países do Continente Africano; e o vernáculo brasileiro à aplicabilidade da língua na fala com suas características próprias da oralidade constituída no nosso país, que não é falada igualmente em Portugal e nem no Continente Africano.

Para o gramático Saconi (2001), a distinção entre fala e escrita se estabelece de maneira que nenhuma se sobreponha a outra em importância nas escolas, principalmente, costuma se ensinar a língua falada com base na língua escrita, considerada superior e isso faz com que a desvalorização da língua falada se torne frequente, além de uma tentativa de igualar a fala com a escrita por questões de valorização de um sistema que segue uma estrutura normativa. A desvalorização evidencia os poucos anos de estudos da Sociolinguística voltados ao assunto, visto que o princípio dos estudos linguísticos de Saussure (1998) direciona a uma visualização da escrita de forma estática, o que não se torna aplicável em situações sociais de uso.

\section{Letramento}

Durante as Séries Iniciais do Ensino Fundamental, quando uma criança rompe a barreira do código e entende como a língua escrita funciona, ela inicia sua caminhada dentro do letramento, pois já é capaz de decodificar símbolos escritos, de captar o sentido de um texto escrito, de fazer comparações, de emitir conclusões, de fazer avaliações, de ampliar o sentido do texto, entre outros; pois "escrever é um processo 
de relacionamento entre unidades sonoras e símbolos escritos, e é também um processo de expressão de ideias e de organização do pensamento sob forma escrita" (SOARES, 2007).

Dessa forma, escrever engloba a aquisição de uso da língua escrita nos seus diferentes aspectos: ortográfico, morfológico, sintático e estilístico em função de uma produção diversificada de materiais. A partir disso, é possível desenvolver as habilidades de leitura e escrita, visto que a linguagem escrita estabelece relações entre leitor e escritor, o que exige, pelo menos, objetivos comuns. 0 escritor tem que saber o porquê e para quem escreve, o leitor, o porquê e para que se lê (FERREIRO, 2001).

É nessa interação que a língua se concretiza e se caracteriza como um processo dinâmico e o leitor/escritor como o sujeito que a (re) constrói em seu dia a dia (FRANCO et al., 1997).Por isso, na escola, o aprendiz deve interagir com diferentes materiais impressos que circulam em seu meio e explorá-los para ampliar e aprimorar a sua competência linguística, para dialogar com seu autor ou para comunicar-se, já que os diferentes gêneros textuais exigem escritor e leitor interessados em determinado tema e "[...] possibilitam novas formas de pensamento; trazem novos conhecimentos, permitem avanços científicos e a busca de soluções..." (FRANCO et al., 1997). Além disso, propicia prazer, no caso, o texto literário, pois envolver-se com a literatura é permitir-se conhecer outros padrões linguísticos, enxergar o mundo através de outros olhos e de pensamentos os mais diversos.

Pode-se afirmar que o letramento é um continuum da alfabetização, visto que os dois processos estão diretamente ligados, embora enfoquem aspectos diferentes. Um indivíduo alfabetizado não é necessariamente um indivíduo letrado, alfabetizado é quem sabe ler e escrever e letrado é quem, além de saber ler e escrever, atende às demandas sociais da leitura e da escrita (FERREIRO et al., 1999).

Desse modo, percebe-se que a alfabetização é contínua, não possui um ponto final, é um processo constante de transformação. Por outro lado, o letramento "é o estado ou condição de quem não apenas sabe ler e escrever, mas cultiva e exerce as práticas sociais que usam a escrita" (SOARES, 2003). Logo, a alfabetização e o letramento ora diferem-se pela sua abrangência, ora fundem-se, já que a alfabetização como processo tem um continuum: o letramento.

É imprescindível salientar que todo falante nativo de uma língua é um falante plenamente competente dessa língua, capaz de discernir intuitivamente a gramaticalidade ou agramaticalidade de um enunciado, isto é, se um enunciado obedece ou não às de funcionamento da língua. Ninguém comete erros ao falar sua própria língua materna, assim como ninguém comete erros ao andar ou respirar (BAGNO, 2007). Com essa afirmação, reflete-se sobre a ordem cronológica em que se estabeleceram a origem da língua e da gramática. A gramática se faz possível pela existência de uma língua já estabelecida dentro de uma estrutura elaborada por falantes na oralidade.

\section{Métodos de Alfabetização no Brasil: breve histórico}

A partir da Proclamação da República, quando a leitura e a escrita passam por um processo crescente e sistemático de escolarização, muitos foram os métodos que se sobrepuseram, que se alternavam e que 
buscavam a hegemonia e a celebração de um grande objetivo: a alfabetização. Eis abaixo alguns métodos de alfabetização e uma abordagem bastante sucinta acerca de cada um deles.

Os Métodos Sintéticos, como o próprio nome já diz, privilegiam e valorizam o processo de síntese. 0 processo de decodificação é realçado, iniciando-se pelas unidades menores da língua, ou seja, letras e sílabas; chegando às maiores e mais complexas (palavra, frase, texto). Há, nesses métodos, a preocupação de que o alfabetizando perceba a correspondência entre o oral e o escrito, entre o som e a grafia. A soletração, a ênfase no aspecto fônico são características de métodos dessa natureza.

Como se percebe, aspectos importantes da alfabetização são contemplados nesses métodos, mas como salienta Bregunci (2004) eles não exploram as complexas relações entre fala e escrita, suas semelhanças e diferenças; além disso, pela ênfase que atribuem à decodificação, resultam, muitas vezes, em propostas que descontextualizam a escrita, seus usos e funções sociais, enfatizando situações artificiais de treinamento de letras, fonemas e sílabas. Os Métodos Analíticos, ao contrário dos anteriores, privilegiam a análise, com uma abordagem que parte do todo, de unidades mais amplas para unidades menores.

Esses métodos contemplam uma das capacidades essenciais ao processo de alfabetização sobretudo o estímulo à leitura de unidades com sentido, pelo reconhecimento global delas. Entretanto, quando incorporados de forma parcial e absoluta, acaba, enfatizando construções artificiais e repetitivas de palavras, frases e textos, muitas vezes apenas a serviço da repetição e da memorização, com objetivo de manter controle mais rígido da sequência do processo e das formas de interação gradual da criança com a escrita (FERREIRO, 2001).

Uma informação importante sobre esses métodos analíticos, é que foram amplamente divulgados e defendidos nos anos que se seguiram a 1890, diante da necessidade nacional de se alfabetizar a população, na recente República. A publicação de cartilhas e a formação de professores objetivava a efetivação plena desses métodos. O que se percebe é que a defesa de teóricos e educadores por um método ou outro, ao longo dos anos, atribuía o sucesso na alfabetização ao método ou a quem o emprega e, infelizmente, desconsidera o sujeito cognoscente. Nas últimas décadas, percebe-se que o debate em torno desses métodos, considerados então como 'tradicionais', vem ocupando posição marginal. A Psicogênese da Língua Escrita, teoria proposta por Emília Ferreiro e Ana Teberosky tem ocupado lugar privilegiado nas abordagens sobre alfabetização.

\section{CONCLUSÕES}

Nesse trabalho, discorreu-se a análise da filosofia de ensino-aprendizagem das Escolas de Ensino Fundamental do Estado de Santa Catarina que se baseiam da doutrina Sociointeracionista. Escolheu-se, também, aliar a conclusão de nosso estudo, com o tópico de formação de professores, pois esta temática, além de estar sendo objeto de análise em trabalhos de natureza diversa, a nosso ver, representa uma das saídas para a melhoria da realidade do ensino no Brasil. O professor das Séries Iniciais (10 ao 5o ano) é chamado, a cada dia, a rever seu papel, sua função enquanto docente, frente a uma sociedade em ritmo acelerado de mudanças, que impõe exigências diferenciadas. 
Nesse contexto, estudos têm buscado pensar em competências necessárias ao professor, destacando-se o trabalho de Perrenoud (2000), no qual são elencadas dez competências que deveriam orientar as formações iniciais e contínuas, contribuir para a luta contra o fracasso escolar e desenvolver a cidadania, recorrer à pesquisa e enfatizar a prática reflexiva dos professores das Séries Iniciais, sendo elas organizar e dirigir situações de aprendizagens; administrar a progressão das aprendizagens; conceber e fazer com que os dispositivos de diferenciação evoluam; envolver os alunos em suas aprendizagens e em seu trabalho; trabalhar em equipe; participar da administração da escola; informar e envolver os pais; utilizar novas tecnologias; enfrentar os deveres e dilemas éticos da profissão; administrar a própria formação contínua.

Perrenoud (2002) nos conduz, ainda, a uma reflexão acerca da importância do professor reflexivo, sendo ele "um profissional que questiona sua tarefa, as estratégias mais adequadas, os recursos que devem ser reunidos, timing a respeitar". Quando se remete à reflexão em torno do professor alfabetizador nas Séries Iniciais, faz-se pertinente discutir e analisar o que se espera desse profissional, quais são suas atribuições e responsabilidades no processo de ensino e aprendizagem.

De acordo com as Diretrizes da BNCC (2017) a formação de docentes para atuar na educação básica far-se-á em nível superior, em curso de licenciatura, de graduação plena, em universidades e institutos superiores de educação, admitida, como formação mínima para o exercício do magistério na educação infantil e nas quatro primeiras séries do ensino fundamental.

Diante disso, assiste-se a uma enorme oferta de cursos de formação de professores, visando atender a essa nova exigência. No entanto, sabe-se muito bem que, aliado a essas políticas de formação de professores, é preciso que haja investimentos em prol da qualidade da formação. O exercício da docência, em qualquer nível de ensino e, particularmente, nas Séries Iniciais que trabalha alfabetização, exige uma formação muito sólida, diante da construção de competências, que se dará, certamente, através de um processo contínuo de formação.

Araújo et al. (2004), membros do INEP, acrescentam a esta reflexão, que é preciso conhecer o perfil dos regentes que atuam nas classes de alfabetização; é importante saber sobre sua formação e ter conhecimento sobre as práticas educacionais por ele implementadas. Após isso, é necessário desencadear um esforço de consenso junto a especialistas e docentes sobre quais habilidades são imprescindíveis na alfabetização das crianças. Essa matriz de habilidades irá orientar um bom processo de capacitação de professores, com objetividade e voltado para a melhoria das práticas pedagógicas no cotidiano escolar.

Diante disso, defende-se a ideia de que cada escola precisa se organizar para que os professores estudem, compartilhem ideias, teorias, opiniões, socializem suas práticas. Trata-se de um movimento de formação sério, coerente com a realidade de cada escola e com uma coordenação democrática, que permita o aperfeiçoamento e crescimento coletivo.

Pensando, especificamente, no professor alfabetizador, faz-se necessário que ele se aproprie de algumas concepções importantes, com as quais desenvolverá o seu trabalho. Certas concepções, como 
criança, educar, cuidar, brincar, são apresentadas de maneira muito clara no Referencial Curricular Nacional para Educação Infantil.

Cabe explicitar aqui a concepção de Criança, que deve perpassar toda prática pedagógica do professor alfabetizador. Deixando-se explicitado que as crianças possuem uma natureza singular, que as caracteriza como seres que sentem e pensam o mundo de um jeito muito próprio. Compreender a criança como ser pensante, com grande potencial e que possui particularidades que devem ser conhecidas e respeitadas, é tarefa do professor.

Diante disso, reforça-se a necessidade da formação em serviço e de um elemento de fundamental importância nesse processo: o planejamento. Através dele, o professor explicita suas concepções, elabora diretrizes de trabalho, organiza a sua rotina, prevê objetivos, habilidades e competências, define conteúdos e metodologias, avalia o progresso dos alunos e a sua atuação docente, enfim, elabora um guia de orientação de sua prática. É, portanto, indispensável o planejamento escolar, em todos os níveis, desde os de caráter coletivo, no qual vários membros da escola participam, quanto os de caráter individual, de competência de cada professor.

\section{REFERÊNCIAS}

ANDRADE, M. M. D.. A metodologia do trabalho científico. São Paulo: Atlas, 1999

BAGNO, M.. Nada na língua é por acaso: por uma pedagogia da variação linguística. São Paulo: Parábola, 2007.

BRASIL. Base Nacional Curricular Comum: Ensino Fundamental: Anos iniciais. Brasília: DOU, 2017.

BRASIL. Diretrizes e Bases da Educação Nacional. Lei n.9394/96. Brasília: DOU, 1996.

BRASIL. Ministério da Educação e do Desporto. Referencial curricular nacional para a educação infantil. Brasília: MEC, 1998.

BREGUNCI, M. G. C.. Organizando as classes de alfabetização: processos e métodos. Campinas: 2004.

FERREIRO, E.. Cultura, escrita e educação. Porto Alegre, Artes Médicas, 2001

FERREIRO, E.; TEBEROSK, A.. Psicogênese da Língua Escrita. Porto Alegre: Artmed, 1999.

FRANCO, Â.; ALVES, Â. C. S.; ANDRADE, R. C.. Construtivismo: Uma ajuda ao professor. 4 ed. Belo Horizonte: Lê, 1997.

GIL, A. C.. Métodos e Técnicas de pesquisa social. 6 ed. São Paulo: Atlas, 2013.

GOODMAN, K. S.. Reading: a psycholinguistic guessing game. Journal of the Reading Specialist, v.4, p.126-135, 1967.

INEP. Instituto Nacional de Estudos e Pesquisas Educacionais. Matrizes curriculares de Referência para o SAEB. Brasília: INEP, 1997.
KAMII, C.. A criança e o número. 23 ed. Campinas: Papirus, 1990.

KOCH, I. V.; ELIAS, V. M.. Ler e escrever: Estratégias de produção textual. São Paulo: Contexto, 2009.

LEMLE, M.. Guia teórico do alfabetizador. 14 ed. São Paulo: Ática, 1999.

MARCONI, M. D. A.; LAKATOS, E. M.. Técnicas de pesquisa: planejamento e execução de pesquisas, amostragens e técnicas de pesquisas, elaboração, análise e interpretação de dados. 8 ed. São Paulo: Atlas, 2017.

PERRENOUD, P.. Dez competências para ensinar. Porto Alegre: Artes Médicas, 2000.

PRODANOV, C. C.; FREITAS, H. C. D.. Metodologia do trabalho científico: métodos e técnicas da pesquisa e do trabalho acadêmico. 2 ed. Novo Hamburgo: Freevale, 2013.

SACCONI, L. A.. Nossa Gramática: teoria e prática. São Paulo. Atual, 2001.

SAUSSURE, F.. A prática reflexiva no ofício do professor: profissionalização e razão pedagógica. Porto Alegre: Artmed, 2002.

SAUSSURE, F.. Curso de Linguística Geral. São Paulo: Cultrix, 1998.

SOARES, M.. Alfabetização e letramento. 5 ed. São Paulo: Contexto, 2007.

SOARES, M.. Letramento: um tema em três gêneros. 2 ed. Belo Horizonte: Autêntica, 2003. 
SOARES, M.. Letrar é mais que alfabetizar. Rio de Janeiro: Jornal do Brasil, 2000.
TFOUNI, L. V.. Letramento e alfabetização. 6 ed. São Paulo: Cortez, 2004.

A CBPC - Companhia Brasileira de Produção Científica (CNPJ: 11.221.422/0001-03) detém os direitos materiais desta publicação. Os direitos referem-se à publicação do trabalho em qualquer parte do mundo, incluindo os direitos às renovações, expansões e disseminações da contribuição, bem como outros direitos subsidiários. Todos os trabalhos publicados eletronicamente poderão posteriormente ser publicados em coletâneas impressas sob coordenação da Sustenere Publishing, da Companhia Brasileira de Produção Científica e seus parceiros autorizados. Os (as) autores (as) preservam os direitos autorais, mas não têm permissão para a publicação da contribuição em outro meio, impresso ou digital, em português ou em tradução. 